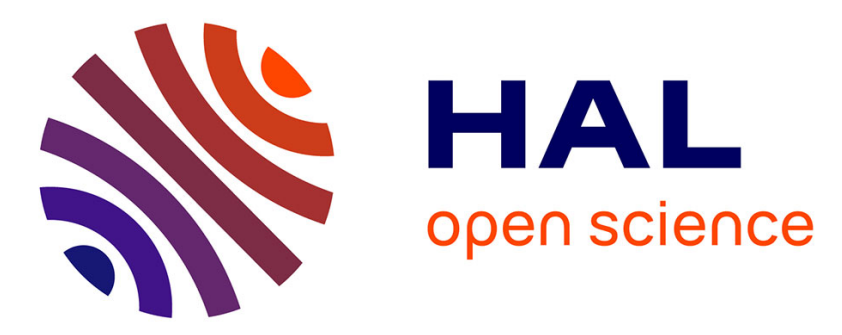

\title{
Synthesis and Shaping Scale-up Study of Functionalized UiO-66 MOF for Ammonia Air Purification Filters
} Y. Khabzina, J. Dhainaut, M. Ahlhelm, H. Richter, H. Reinsch, N. Stock, D. Farrusseng

\section{- To cite this version:}

Y. Khabzina, J. Dhainaut, M. Ahlhelm, H. Richter, H. Reinsch, et al.. Synthesis and Shaping Scale-up Study of Functionalized UiO-66 MOF for Ammonia Air Purification Filters. Industrial and engineering chemistry research, 2018, 57 (24), pp.8200-8208. 10.1021/acs.iecr.8b00808 . hal-01836059

\section{HAL Id: hal-01836059 \\ https://hal.science/hal-01836059}

Submitted on 27 Mar 2019

HAL is a multi-disciplinary open access archive for the deposit and dissemination of scientific research documents, whether they are published or not. The documents may come from teaching and research institutions in France or abroad, or from public or private research centers.
L'archive ouverte pluridisciplinaire HAL, est destinée au dépôt et à la diffusion de documents scientifiques de niveau recherche, publiés ou non, émanant des établissements d'enseignement et de recherche français ou étrangers, des laboratoires publics ou privés. 


\title{
Synthesis and shaping scale-up study of functionalized UiO-66 MOF for ammonia air purification filters
}

\author{
Yoldes Khabzina $^{(1)}$, Jeremy Dhainaut ${ }^{(1)}$, Mehdi Bessaa ${ }^{(1)}$, Matthias Ahlhelm ${ }^{(2)}$, Hans-Juergen Rich- \\ ter $^{(2)}$, Helge Reinsch ${ }^{(3,4)}$, Norbert Stock ${ }^{(3)}$, David Farrusseng ${ }^{(1) *}$ \\ (1) Université de Lyon 1, UMR CNRS 5256, Institut de recherches sur la catalyse et l'environnement, IRCELYON, 2 \\ Ave Albert Einstein, F-69626 Villeurbanne, France. \\ ${ }^{(2)}$ Fraunhofer-Institute for Ceramic Technologies and Systems (IKTS), Winterbergstrasse 28, 01277 Dresden, Ger- \\ many. \\ (3) Institut für Anorganische Chemie, CAU Kiel, Max-Eyth-Straße 2, 24118 Kiel, Germany. \\ ${ }^{(4)}$ MOF Application Services, 25-27 rue Tronchet, 75008 Paris, France
}

KEYWORDS. Ammonia adsorption, breakthrough measurements, UiO66-COOH

\begin{abstract}
We report herein the upscaled synthesis and shaping of $\mathrm{UiO} 66-\mathrm{COOH}$ for $\mathrm{NH}_{3}$ air purification. The synthesis of the zirconium-based MOF was carried out in a batch reactor in an aqueous suspension with a yield of $89 \%$ and a spacetime yield of $350 \mathrm{~kg} / \mathrm{day} / \mathrm{m}^{3}$. Neither toxic chemicals nor organic solvents were used, allowing this MOF to be employed in individual or collective air purification devices. Freeze-granulation and extrusion shaping techniques were investigated. The $\mathrm{NH}_{3}$ air purification performances of $\mathrm{UiO66-COOH}$ in bead, tablet and extrudate forms were compared to those of commercial carbon based materials (type K adsorbents from3 3 and Norit). Testing conditions were chosen to reflect current standards for ammonia concentration (60o-1200 ppm) and velocity. In addition, the breakthrough measurements were carried out at three different relative humidity levels ( $0 \%, 40 \%$ and $70 \%$ ). Pellets and extrudates of UiO66-COOH outperformed commercial benchmark adsorbents in all conditions, especially in dry conditions, for which the commercial adsorbents suffered impaired ammonia uptake and shortened service life. Extrudates of UiO66- $\mathrm{COOH}$ also withstood attrition after intensive shaking.
\end{abstract}

\section{INTRODUCTION}

Impregnated carbons are state-of-the-art adsorbents for ammonia air purification. They are commercialized in the form of type $\mathrm{K}$ cartridges for individual gas protection. They show poor aging characteristics, however, due to deleterious interactions of the mobile active phase with the carbon $^{1}$. Various studies have investigated how MOFs perform for the air filtering of Toxic Industrial Chemicals (TIC), particularly $\mathrm{NH}_{3} 3^{1,2,3,3,4,6,7,8,8,9,1,1,11}$. For the latter, high ammonia adsorption capacities under both dry and humid conditions have been dynamically measured for UiO-66$\mathrm{NH}_{2}$, Ni-CPO-27, Fe-MIL-10o and HKUST-1 ${ }^{12}$. It was underlined that in addition to adsorption performances, the chemical and mechanical stabilities and cost issues should also be addressed ${ }^{12}$. Extra factors to carefully consider are process and user safety. Unfortunately, up to now, MOFs have usually been synthesized in organic solvents such as DMF, especially those being tested for TIC abatement ${ }^{2,3,13,1,1,15,1,6,7,9}$. DMF is a toxic chemical considered to present a health hazard: it can cause various accidents and birth defects ${ }^{16}$, its inhalation results in liver damage, and it causes digestive disturbances in workers ${ }^{17}$. As a consequence, DMF should not be used as the synthesis solvent for breathable air filtration devices even if extensive washing is carried out.

Shaping the adsorbent with the appropriate particle size and density is a practical prerequisite. In an individual protection cartridge, the size of the adsorbent grains is generally between 12 and 20 mesh $^{18}$ (corresponding to $1680-840$ $\mu \mathrm{m})$. Smaller particles would result in an excessive pressure drop, i.e., breathing resistance, which cannot be accepted by the users 5 . For the same reason, the shaped adsorbent must not decompose into fine particles upon shaking or similar mechanical stress. Although it is acknowledged that shaping processes can often affect performances in comparison to the original powder, the effect of shaping on adsorption capacities is rarely reported ${ }^{1,12}$, especially regarding the volumetric adsorption capacity. Indeed, to the best of our knowledge, adsorption capacity is always reported by unit of mass, yet volumetric capacity is a key criterion because the cartridge volume is limited, especially for face mask filters. Unfortunately, both bulk and tapped 
densities of shaped MOFs are rarely reported, thereby preventing the volumetric extrapolation of uptakes ${ }^{19,20}$. In addition, novel adsorbents are rarely benchmarked under relevant conditions, rendering impossible any rational comparison with suitable commercial adsorbents for the application in question. This is the case not only for service lifetime, i.e., breakthrough time, but also for aging and mechanical stability.

Among MOF candidates that have shown high $\mathrm{NH}_{3}$ adsorption capacities in dynamic and humid conditions, UiO-type MOFs are recognized to be exceptionally stable over a wide range of $\mathrm{pH}$, humidity, temperature and pressure conditions, ${ }^{5,21,22}$. The $\mathrm{UiO}-66$ class is based on $\mathrm{Zr}_{6} \mathrm{O}_{4}(\mathrm{OH})_{4}$ octahedral nodes that form lattices in an ideal 12-fold coordination with dicarboxylic linkers, resulting in a cubic close-packed unit cell structure. The high zirconium charge and the elevated connectivity of the nodes account for exceptionally good chemical, thermal and mechanical resistance ${ }^{5,23}$. Following the suggestions of Kim et al. ${ }^{8}$, it was anticipated that functionalizing the UiO-66 with free carboxylic acid would facilitate $\mathrm{NH}_{3}$ adsorption by Brønsted-type acid-base interactions. Recently, Joshi et al. showed that solid UiO66-COOH made from 1,2,4-benzenetricarboxylic acid in DMF performs equally well in dry and humid conditions for ammonia capture $(2.2 \mathrm{mmol}$ $\left.\mathrm{NH}_{3} / \mathrm{g}\right)^{13}$.

The "green" synthesis of MOFs, especially Al- and ZrMOFs in water, is now well documented and has been recently reviewed ${ }^{24}$ with a focus on requirements discussed by industrial research groups for MOF synthesis upscaling $^{25}$. Beyond the benefit presented by non-toxic solvents for the specific case of breathable filters, water-based synthesis would enable a substantial decrease in production $\operatorname{costs}^{26}$. That said, it is now well known that different synthesis methods and work-up processes may yield different crystalline and porous structures, especially for UiO-66 type MOFs, for which the nature and concentration of defects are very process-sensitive ${ }^{27,28}$. It has been shown that water adsorption properties, hydrophilicity and total water capacities depend on defect concentration in $\mathrm{UiO}-66^{29,30,31}$. Hence, we can assume that $\mathrm{NH}_{3}$ adsorption performance in humid conditions may also depend on the nature and concentration of defects resulting from different synthesis processes, which provides an additional reason for this investigation.

Here we present a benchmark study for the upscaled synthesis and shaping of UiO66-COOH that addresses key aspects for a potential industrialization, more specifically: (i) exclusive use of water for the synthesis, washing and shaping, (ii) use of non-explosive and non-corrosive starting chemicals, (iii) development of scalable shaping techniques and (iv) investigation of the mechanical and chemical stability of the shaped MOF. We show that the performances of the shaped $\mathrm{UiO} 66-\mathrm{COOH}$ are superior to those of commercial type $\mathrm{K}$ adsorbents for $\mathrm{NH}_{3}$ air purification in relevant dynamic conditions covering a wide range of humidity levels. This paper can be regarded as a preliminary step toward a technical-economic study of UiO66-
$\mathrm{COOH}$ as a type $\mathrm{K}$ air filter. The precise costs of large-scale production of a MOF and its shaping are beyond the scope of this study ${ }^{26}$.

\section{EXPERIMENTAL}

Two types of commercial type K adsorbents were used here as benchmarks: (1) granules of activated carbon of 1220 mesh $^{18}$ commercialized by $3 \mathrm{M}$ and (2) Norit RZN1 extrudates of zinc salt-impregnated carbon. For breakthrough measurements, both materials were gently grinded and sieved to obtain a fraction between $425 \mu \mathrm{m}$ and $600 \mu \mathrm{m}$.

\section{Small-scale synthesis of UiO66-COOH}

A $10 \mathrm{mmol}$ quantity of zirconium (IV) sulfate and 11 mmol of 1,2,4-benzenetricarboxylic acid were mixed together in $30 \mathrm{~mL}$ water. The synthesis was carried out under refluxing for 90 minutes. After that, the mixture was filtered, washed three times with distilled water on the filter and dried in air at $120^{\circ} \mathrm{C}$. After drying, $2.77 \mathrm{~g}$ of white powder was obtained, representing a yield of $87 \mathrm{wt} . \%$.

\section{Scaled-up synthesis of $\mathrm{UiO66-COOH}$}

A $12 \mathrm{~L}$ double-wall batch reactor was used. The reactant dispersion was mixed using an anchor-shaped mechanical stirrer at $100 \mathrm{rpm}$. An $8 \mathrm{~L}$ volume of deionized water and $1000 \mathrm{~g}(4.8 \mathrm{~mol})$ of trimellitic acid from Sigma Aldrich were mixed together in a $12 \mathrm{~L}$ glass reactor. The initially white slurry became translucent above $70^{\circ} \mathrm{C}$. The temperature inside the reactor reached $80^{\circ} \mathrm{C}$ after $2 \mathrm{~h}$. At that moment, $736 \mathrm{~g}$ of zirconium sulfate tetrahydrate from AlfaAeser (2 mol) were added, and the mixture was kept under stirring for another $3 \mathrm{~h}$ while the temperature continued to increase. After $3 \mathrm{~h}$, the temperature within the reactor reached $91^{\circ} \mathrm{C}$. The heating was then switched off, and cooling was applied before the slurry was removed from the bottom of the reactor. The slurry was filtered on a Büchnertype setup, and then washed with $10 \mathrm{~L}$ of deionized water in three steps. The resulting white powder was then dried in an oven for $24 \mathrm{~h}$ at $120^{\circ} \mathrm{C}$ under air flow $\left(1^{\circ} \mathrm{C} / \mathrm{min}\right.$ heating and cooling ramps). After drying, $647 \mathrm{~g}$ of white powder was obtained, representing a yield of $89 \mathrm{wt} . \%$. The spacetime yield was about $350 \mathrm{~kg} /$ day $/ \mathrm{m}^{3}$.

For breakthrough measurements, $1.5 \mathrm{~g}$ of powder was pressed to pellets under a pressure of 97 bar using a die of $3 \mathrm{~cm}$ in diameter. A force of $588 \mathrm{o} \mathrm{N}$ was applied to the die and held for 1 minute. The resulting pellets were gently crushed and sieved in a particle size range between $425 \mu \mathrm{m}$ and $600 \mu \mathrm{m}$.

\section{Characterization}

Powder X-ray diffraction (XRD) patterns of the solids were recorded on a Bruker (Siemens) D5005 diffractometer using $\mathrm{Cu} \mathrm{K} \alpha$ radiation. Diffractograms were collected between 4 and $80^{\circ}(2 \theta)$ with steps of $0.02^{\circ}$ and $1 \mathrm{~s}$ per step. $\mathrm{N} 2$ isotherms at $77 \mathrm{~K}$ were measured by manometry using 
a BelMini device (BelJapan). Prior to measurement, the samples were activated under vacuum at $150^{\circ} \mathrm{C}$ overnight. The surface area and micropore volume were calculated using BET and t-plot methods, respectively. Particle size distribution analysis was conducted using a Microtrac S350o laser granulometry apparatus. A very small amount of powder was dispersed in deionized water. In order to facilitate the desagglomeration, ultrasonic irradiation was applied for $30 \mathrm{~s}$ or $60 \mathrm{~s}$. Thermogravimetric analysis (TGA) was carried out on a Mettler Toledo TGA-DSC 1 apparatus using reconstituted air; in this case, $\mathrm{UiO} 66-\mathrm{COOH}$ powder was heated from $25^{\circ} \mathrm{C}$ to $800^{\circ} \mathrm{C}$ with a ramp of $5^{\circ} \mathrm{C} / \mathrm{min}$. Bulk densities of pellets, extrudates and beads of UiO66$\mathrm{COOH}$ were measured. It corresponds to the ratio of the pellet mass or $(n)$ extrudates or beads $(n=10)$ to volume of each pellet, $(\mathrm{n})$ extrudates or beads. Extrudates are cylinders with $3 \mathrm{~mm}$ length and $1.5 \mathrm{~mm}$ diameter. Beads are spheres of $3.76 \mathrm{~mm}$ in diameter. Pellets are disks of $3 \mathrm{~cm}$ in diameter and $3 \mathrm{~mm}$ in height.

\section{Shaping by freeze granulation}

Deionized water (74 vol.\%) was mixed manually with a dispersant and binding agent (polyvinyl alcohol: 4 vol.\% relative to the MOF). Subsequently, the MOF was added (22 vol.\%). This mixture was then stirred manually again prior to being transferred into a centrifugal vacuum mixer (Thinky ARV310), where it was exposed to a high stirring rate (200o rpm, mixing time 2 minutes, with $\mathrm{ZrO}_{2}$ mixing spheres) in order to disperse the particles and reduce agglomeration. Afterward, the suspension was separated from the mixing spheres by being cast through a $130 \mu \mathrm{m}$ sieve and then poured into a syringe. Under controlled pressure the suspension was next deposited dropwise into liquid nitrogen. Upon contact with the liquid $\mathrm{N}_{2}$ the drops of suspension instantaneously froze into spherical granules. These frozen beads were transferred to a freeze-dryer for sublimation of the solvent. As a result of this procedure, MOF beads were obtained; they averaged about $2.35 \mathrm{~mm}$ in diameter.

For micro-breakthrough measurements, the beads were gently ground and sieved to obtain a particle size range between $425 \mu \mathrm{m}$ and $600 \mu \mathrm{m}$.

\section{Shaping by extrusion}

The extrusion paste was prepared using the kneading chamber of a Brabender Plastograph measuring kneader. A $60 \mathrm{~g}$ mass of MOF powder was placed inside the doubleblade kneading chamber, and then water and the binder system were added under a constant rotational speed of 50 $\mathrm{rpm}$. The mixing and plasticization process was performed for $30 \mathrm{~min}$ at room temperature. The prepared paste contained 72.5 vol.\% UiO66-COOH, 22 vol.\% water and 5.5 vol.\% polysiloxane (silicon resin)-based binder. The extrusion was performed using laboratory piston extrusion equipment with a nozzle diameter of $1.5 \mathrm{~mm}$. Lines of approximately $300 \mathrm{~mm}$ in length were extruded, dried at room temperature and then cut into small cylinders of about $1.5 \mathrm{~mm}$ length (hereafter referred to as extrudates).

For micro-breakthrough measurements, the cylinders were gently ground and sieved to obtain a granulometry between $425 \mu \mathrm{m}$ and $600 \mu \mathrm{m}$.

Figure 1 shows the different shapes of UiO66-COOH and the commercial type K adsorbent.

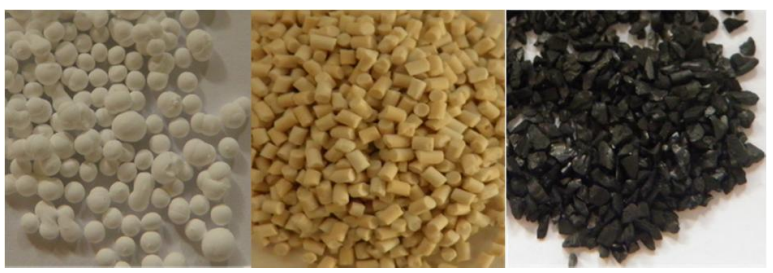

Figure 1. Photographs of beads obtained by freeze granulation (left), extrudates (center) and commercial type K adsorbent from $3 \mathrm{M}$ (right).

\section{Aging of UiO66-COOH}

To investigate the impact of aging on ammonia adsorption performance, a compacted pellet of $\mathrm{UiO} 66-\mathrm{COOH}$ was aged under the same conditions as those reported by Hindocha et al. ${ }^{12}$ at $80 \%$ RH for 7 days. Aged UiO66-COOH was tested under a flow of $1200 \mathrm{ppm} \mathrm{NH}_{3}$ and $40 \% \mathrm{RH}$.

\section{Attrition test of shaped UiO66-COOH}

Attrition tests were conducted to assess the percentage amount of fine particles that the respective shaped materials can generate in the event of shaking or falling ${ }^{12}$. A $0.2 \mathrm{~g}$ mass of material was introduced into a cylinder of $3 \mathrm{~cm}$ internal diameter $x 2.5 \mathrm{~cm}$ height containing an obstacle that the materials hit. This cylinder was made to turn on a classic tube roller (RSLAB-10) at a frequency of 60 rotations per minute (rpm) for 30 minutes. Afterward, the content was passed through a $425 \mu \mathrm{m}$ sieve to recover fine particles. Attrition percentage is calculated as follows:

$$
\text { Attrition }=\frac{\text { initial mass }- \text { recovered mass above } 425 \mu \mathrm{m}}{\text { initial mass }} \times 100
$$

Equation 1

\section{Micro-breakthrough measurements}

Assessment of $\mathrm{NH}_{3}$ filtering was carried out by microbreakthrough measurements similar to the methods reported elsewhere ${ }^{12,7}$. The setup is presented in Figure 2. Humid conditions were generated by humidifying a controlled flow of diluted $\mathrm{N}_{2}$ to obtain a stream of $100 \mathrm{~mL} / \mathrm{min}$ with relative humidity of $40 \%$ or $70 \%$. The concentration of $\mathrm{NH}_{3}$ and water at the outlet were monitored online by an infrared spectrometer (Nicolet iSio FT-IR) equipped with an insulated 2-meter gas cell (of $200 \mathrm{~mL}$ volume) from Thermo Fisher Scientific. A makeup flow of $440 \mathrm{~mL} / \mathrm{min}$ was applied in order to renew the cell volume every $27 \mathrm{~s}$, 
thus increasing the time resolution by a factor of approximately three. The frequency of acquisition was set to one analysis per $50 \mathrm{~s}$.

The sieved powder $(425-600 \mu \mathrm{m})$ was packed into a constant volume of $0.15 \mathrm{~cm}^{3}$ inside a $7-\mathrm{mm}$ internal diameter fritted glass tube, to a height of $4 \mathrm{~mm}$. The sieved fraction size, column dimension and flow rate are of the same order as those previously reported by Hindocha et $\mathrm{al}^{12}$. The advantages of testing a sieved fraction are that (i) a relatively high flow rate can be used without a significant pressure drop, making it possible to discriminate between adsorbents with/without internal diffusion limitations ${ }^{1}$ and (ii) it enables the comparison of adsorbents that were originally of different shapes and bulk densities since column packing and pressure drop should be the same.

Sorbents were first heated at $150^{\circ} \mathrm{C}$ for 30 minutes in flowing dry $\mathrm{N}_{2}$. Breakthrough measurements were carried out at $22^{\circ} \mathrm{C}$ under o\% (dry), $40 \%$ and $70 \% \mathrm{RH}$ in separate measurements starting with fresh samples. The challenge concentration was fixed at $1200 \mathrm{ppm} \mathrm{NH}_{3}$ for $\mathrm{0} \%$ and $40 \%$ $\mathrm{RH}$ and at $600 \mathrm{ppm}$ for $70 \% \mathrm{RH}$. For measurements under humid conditions, the sample was pre-equilibrated under humid stream flow at $40 \%$ or $70 \% \mathrm{RH}$. The water concentration at the outlet of the column was monitored until the adsorbent was saturated, permitting the water uptake at equilibrium to be quantified.

Micro-breakthrough graphs are plotted versus time in order to reflect the performance of the shaped materials for a given bed volume. The breakthrough time corresponds to the first time in minutes at which ammonia breaks through (concentration $>25 \mathrm{ppm}$ ) and is the relevant practical indicator for the performance of a shaped adsorbent because it defines the service life of the device. For comparison purposes with other studies, ammonia adsorption capacity is calculated by integrating under the breakthrough curve, using the trapeze method. The calculation of ammonia adsorption capacity $\mathrm{W}$ in $\mathrm{mg}$ is as follows:

$$
W=\left(C_{0} t_{s}-\sum_{t=0}^{t_{s-1}} \frac{C_{n}+C_{n-1}}{2}\left(t_{n}-t_{n-1}\right)\right) \times \frac{F_{t} \times M \times 10^{-3}}{V_{m}}
$$

Equation 2

The standard error is approximately $6 \%$.

Plots of outlet ammonia concentration and corresponding uptake capacity expressed per unit of mass can be found in the SI.

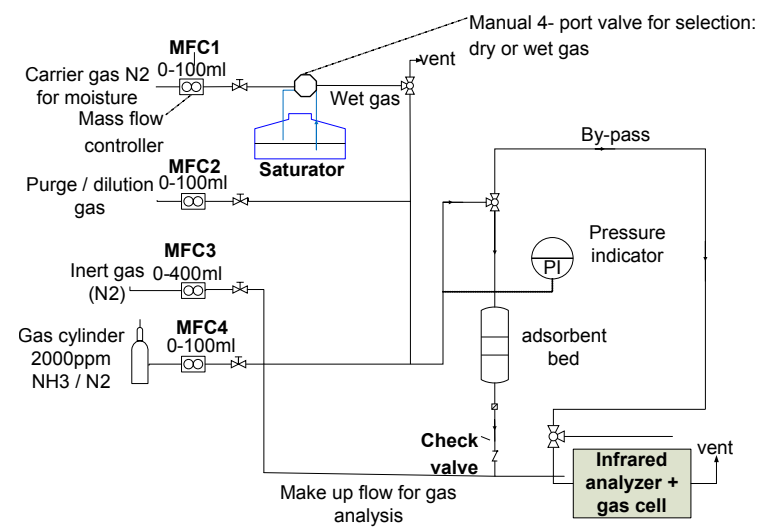

Figure 2. Diagram of the micro-breakthrough test rig.

\section{RESULTS AND DISCUSSION}

After the washing step, the powder obtained by largescale synthesis was divided into four samples (Batch-1 to Batch-4) that were dried and characterized separately. Powder XRD, presented in Figure 3, shows highly crystalline samples that are very similar to those obtained from the small-batch synthesis. The patterns are also in excellent agreement with the theoretical pattern simulated from the reported crystal structure ${ }^{32}$. Finally, the TGA profile (Fig. S6) is also very similar to the data reported by Ragon et $\mathrm{al}^{32}$.

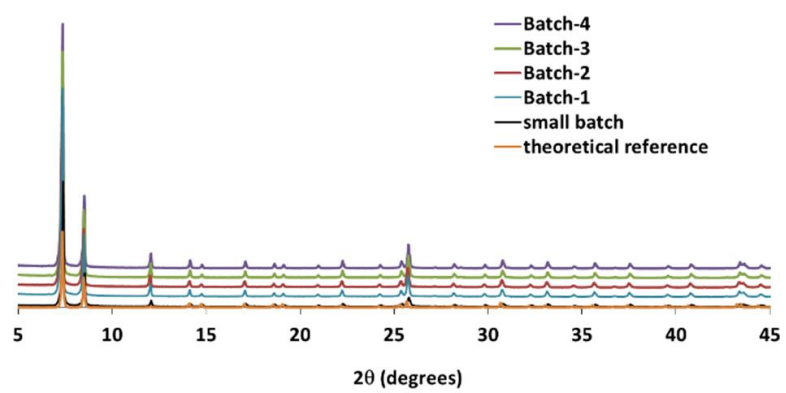

Figure 3. Powder X-ray diffractograms of the four samples from Batch-1 to -4 compared to the small-batch synthesis (black line) and to the theoretical reference (orange line).

Laser granulometry was applied to evaluate the size of the primary particles. The particle size distribution is shown in Figure 4. The as-activated powder presents particle sizes between 0.9 and $10 \mu \mathrm{m}$. After deagglomeration by ultrasonic irradiation, $90 \%$ of the particle size distribution is between 0.4 and $1 \mu \mathrm{m}$. 


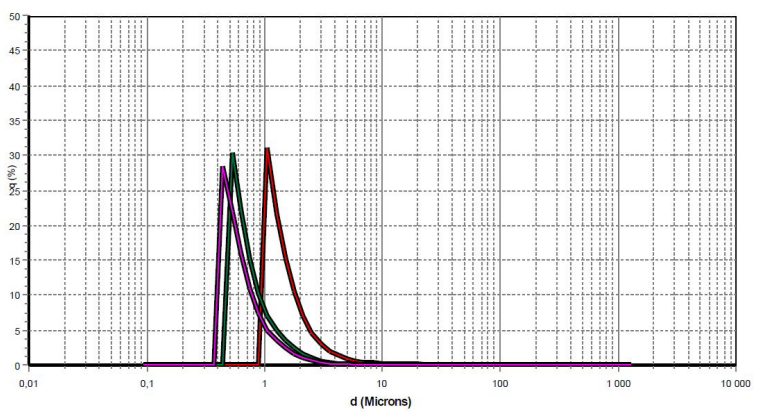

Figure 4. Particle size distribution of UiO-66-COOH (Batch-1) as-obtained (red), and after $30 \mathrm{~s}$ (green) and 6o s (pink) of ultrasonic irradiation.

Nitrogen adsorption isotherms are reported in Figure 5. High specific surface area $\left(710 \mathrm{~m}^{2} / \mathrm{g}\right)$ and micropore volume $\left(0.28 \mathrm{~cm}^{3} / \mathrm{g}\right)$ were obtained for an upscaled UiO66$\mathrm{COOH}$, in excellent agreement with Ragon et al ${ }^{32}$. While the compression is detrimental to the textural properties of the original UiO66- $\mathrm{COOH}$ powder, the specific surface areas of the extrudates and beads are about $418 \mathrm{~m}^{2} / \mathrm{g}$ and $359 \mathrm{~m}^{2} / \mathrm{g}$, respectively. We note, here, a decrease of about $50 \%$ in both the specific surface area and the micropore volume after freeze granulation and extrusion. This may be due to the addition of the plasticizer, which prevents $\mathrm{N}_{2}$ from reaching the pore at $77 \mathrm{~K}$ compared to the original powder, and/or to anhydride formation from adjacent linkers upon heating, which has a direct impact on N2 physisorption measurements ${ }^{32}$. We note a good correlation between water uptake at $40 \%$ relative humidity and the micropore volume measured by $\mathrm{N}_{2}$ physisorption (Table 1).

The main difference between the shaped materials lies in their bulk density. While the compressed powder (tablet) presents a density of $0.62 \mathrm{~cm}^{3} / \mathrm{g}$, the extrudate is much denser at $1.04 \mathrm{~cm}^{3} / \mathrm{g}$, and the beads are much less dense at $0.12 \mathrm{~cm}^{3} / \mathrm{g}$. This contrast originates from the shaping techniques, which allow dissimilar crystallite packing and thus a specific macroporosity in the grain, the most porous form being the beads obtained by freeze granulation. As a direct consequence, $\mathrm{NH}_{3}$ uptake values per unit of mass and volume strongly differ.

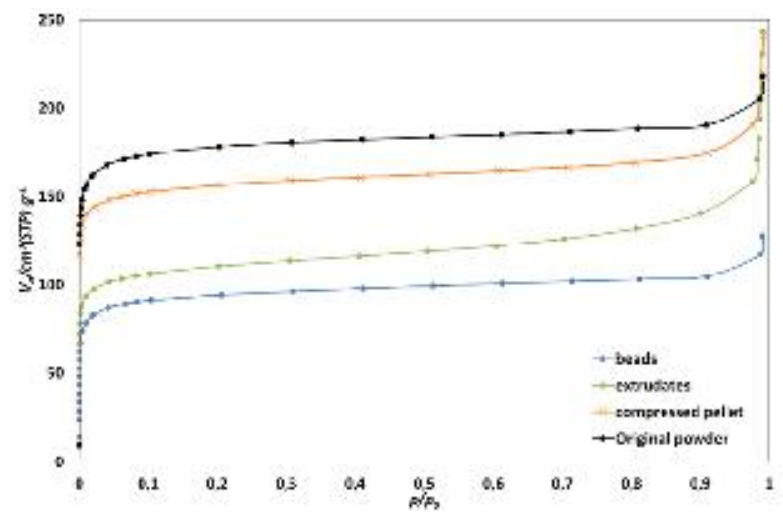

Figure 5. Nitrogen adsorption isotherms of the shaped UiO66- $\mathrm{COOH}$ samples at $77 \mathrm{~K}$.
Table 1. Textural properties of shaped UiO66-COOH

\begin{tabular}{|l|c|c|c|c|}
\hline & $\begin{array}{c}\text { Bulk } \\
\text { density } \\
\left(\mathrm{g} / \mathrm{cm}^{3}\right)\end{array}$ & $\begin{array}{c}\text { Surface } \\
\text { area } \\
\left(\mathrm{m}^{2} / \mathrm{g}\right)\end{array}$ & $\begin{array}{c}\text { Mi- } \\
\text { cropore } \\
\text { volume } \\
\left(\mathrm{cm}^{3} / \mathrm{g}\right)\end{array}$ & $\begin{array}{c}\text { Water up- } \\
\text { take at } \\
\mathrm{RH}=40^{\mathrm{f}}{ }^{\mathrm{f}} \\
\left(\mathrm{cm}^{3} / \mathrm{g}\right)\end{array}$ \\
\hline $\begin{array}{l}\text { Original } \\
\text { powder }\end{array}$ & n.a. & 710 & 0.28 & n.a. \\
\hline $\begin{array}{l}\text { Compressed } \\
\text { Pellet }\end{array}$ & 0.62 & 614 & 0.24 & 0.26 \\
\hline Extrudates & 1.04 & 418 & 0.15 & 0.19 \\
\hline Beads & 0.12 & 359 & 0.12 & 0.12 \\
\hline
\end{tabular}

§ from BET analysis of $\mathrm{N}_{2}$ physisorption at $77 \mathrm{~K}$

\# from t-plot analysis of N2 physisorption at $77 \mathrm{~K}$

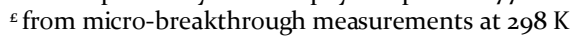

Figure 6, Figure 7 and Figure 8 represent ammonia breakthrough curves of shaped UiO66- $\mathrm{COOH}$ and commercial type $\mathrm{K}$ adsorbents under dry, wet conditions at 40 and $70 \% \mathrm{RH}$, respectively. We can observe that the breakthrough time and the profiles of the curves are relatively similar for the two benchmark adsorbents from $3 \mathrm{M}$ and Norit. We can also observe the same ranking of the adsorbents under dry and humid conditions. The UiO-COOH beads break first, followed by the $\mathrm{AC}$ reference materials, the compressed $\mathrm{UiO}-\mathrm{COOH}$ and finally the extrudate. We notice that the shape of the breakthrough curves remains very similar regarding the rate at which the concentration increases when $\mathrm{NH}_{3}$ breaks through, except for the beads, for which the breakthrough profile is much steeper. In this study, the grain sizes are identical because the samples were sieved from $425 \mu \mathrm{m}$ to $600 \mu \mathrm{m}$, so we can rule out any differences in external diffusion processes. We suggest that the difference in the breakthrough slope could be caused by for slow kinetics involving internal mass transfer limitations, as already reported for compressed pellets of UiO66$\mathrm{NH}_{2}{ }^{1}$. We suppose that minor internal diffusion limitations could occur, i.e., inside the porosity of the grains, with the exception of the beads, which have a very high internal porosity.

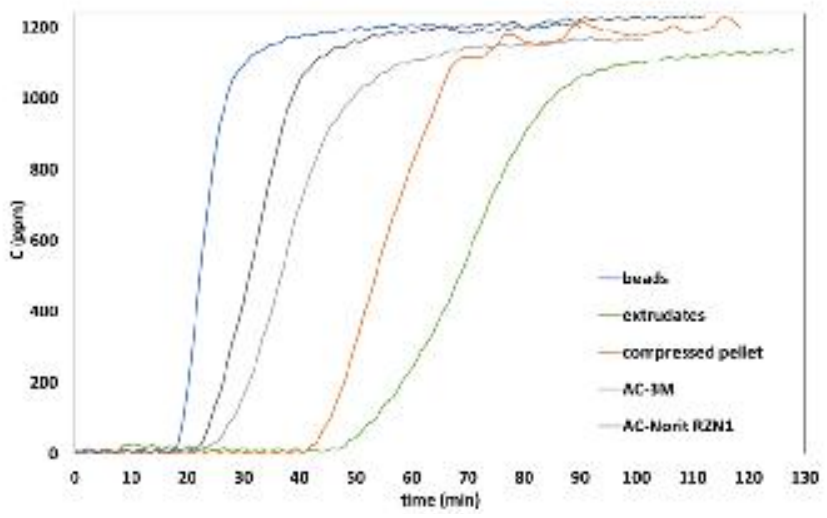

Figure 6. Comparison between ammonia breakthrough curves of commercial type K adsorbents as benchmark materials and shaped UiO66-COOH (1200 ppm NH 3 , o\% RH). 


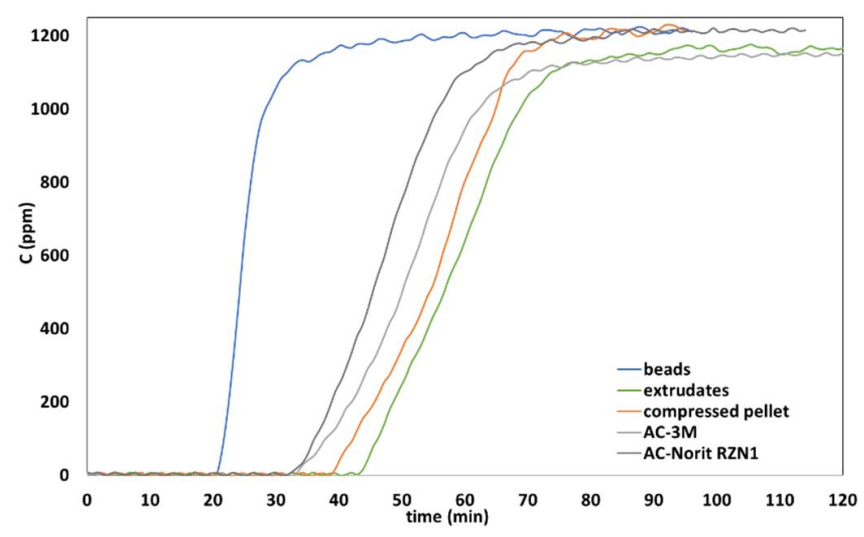

Figure 7. Comparison between ammonia breakthrough curves of commercial type K adsorbents as benchmark materials and shaped UiO66-COOH (1200 ppm $\mathrm{NH}_{3}, 40 \% \mathrm{RH}$ ).

Performance indicators of shaped MOFs and benchmark materials are summarized in Table 2 . In practice, we could quantitatively rank the adsorbents by increasing breakthrough time because the measurements are carried out on the same bed volume. We found a relatively good correlation between the breakthrough time and the uptake capacity per unit volume (see SI). This linear correlation across the sample series arises from the similar wavefront profiles of the breakthrough curves. As a consequence, we prefer here to discuss the uptake values per unit volume rather than the breakthrough time values. The uptake values per unit mass can be calculated using the packed density values (see SI).

Under dry conditions (o\% RH), UiO66-COOH compressed pellet and extrudates outperform by far the commercial adsorbents, with double breakthrough time and a noteworthy ammonia adsorption capacity (Figure 6). The uptake for the UiO66-COOH beads is much lower because of their very low density. However when compared on a mass basis, the beads rank at the same level as the $3 \mathrm{M}$ adsorbent.

At $40 \%$ relative humidity, the breakthrough time and ammonia uptakes are enhanced for the commercial adsorbents. A beneficial effect of humidity on $\mathrm{NH}_{3}$ uptake in activated carbon-based adsorbents has already been reported elsewhere ${ }^{33}$, while the mechanism of ammonia uptake in humid conditions has previously been found over a diverse set of adsorbents ${ }^{34}$. In contrast to the activated carbons, the performances in humid conditions remain almost unchanged for the UiO-66-COOH compressed pellet and extrudates. At higher relative humidity $(70 \%)$ and at $600 \mathrm{ppm}$ of $\mathrm{NH}_{3}$, the ammonia uptake for the $\mathrm{UiO}-66-\mathrm{COOH}$ compressed pellet is $31 \mathrm{mg} / \mathrm{cm}^{3}$ versus 26 for the $3 \mathrm{M}$ adsorbent, which is also reflected by a longer breakthrough time, 81 min versus $75 \mathrm{~min}$ (c. $f$ Figure 8 ).

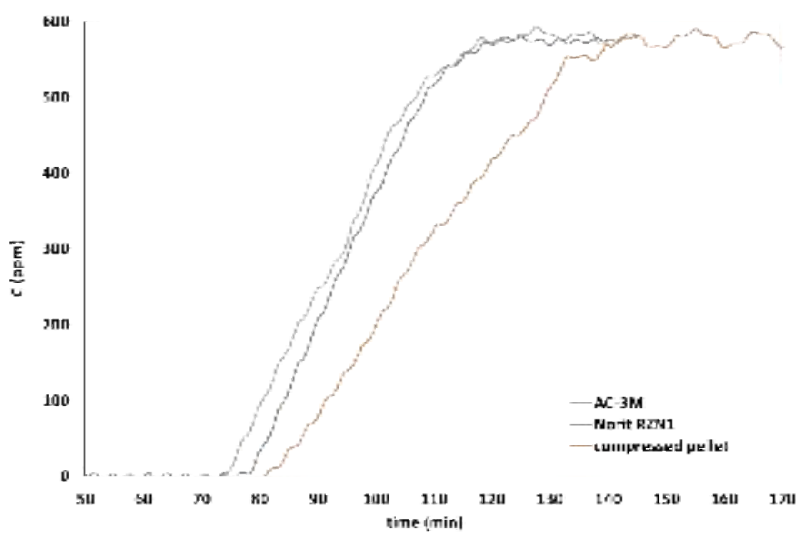

Figure 8. Comparison between ammonia breakthrough curves of commercial type K adsorbents as benchmark materials and compressed/sieved UiO66-COOH (6oo ppm NH $3,70 \% \mathrm{RH}$ ).

In all conditions tested, the $\mathrm{UiO}-66-\mathrm{COOH}$ compressed pellet and extrudates outperform the commercial adsorbents in terms of capacity per unit volume and breakthrough time. The outstanding performances of UiO-66$\mathrm{COOH}$ can be explained in part by the relatively high bulk density of the pellet and extrudates. In addition, even comparing the uptake by unit of mass, the $\mathrm{UiO}-66-\mathrm{COOH}$ pellet and extrudates ( 55 and $53 \mathrm{mg} / \mathrm{g}$, respectively) outperform the commercial Norit and $3 \mathrm{M}$ adsorbents (30 and 39 $\mathrm{mg} / \mathrm{g}$, respectively).

The ammonia uptake values in dry conditions obtained here are significantly higher than published data for $\mathrm{UiO}-$ $66-\mathrm{COOH}$ powders ${ }^{13}$. Here, we found uptakes of $55 \mathrm{mg} / \mathrm{g}$ as opposed to $38 \mathrm{mg} / \mathrm{g}^{13}$, which is significantly lower. The differences in uptakes may originate from different surface chemistry and/or concentration defects resulting from the synthesis process ${ }^{35,36,37}$. While the upscaled synthesis is carried out here in water using $\mathrm{Zr}$ sulfate as precursor, the adsorbent in the literature ${ }^{13}$ was prepared in DMF starting with zirconium oxynitrate hydrate as precursor. We also note a major difference in the water uptake at $40 \%$ relative humidity, i.e., $0.26 \mathrm{~cm}^{3} / \mathrm{g}$ in this study compared to 0.04 $\mathrm{cm}^{3} / \mathrm{g}$ for Joshi et al. ${ }^{13}$, while both solids exhibit almost the same micropore volumes of $0.24 \mathrm{~cm}^{3} / \mathrm{g}$ and $0.28 \mathrm{~cm}^{3} / \mathrm{g}$, respectively. This simultaneous difference in water uptake and near-sameness of micropore volume supports the assumption that the synthesis in water may generate a higher concentration of surface hydroxyl groups, which are favorable for water and ammonia adsorption ${ }^{29,30,31}$.

Regenerability of UiO66-COOH as compressed pellet was tested by reactivating the material at $150^{\circ} \mathrm{C}$ for 1 hour with a ramp of $10^{\circ} \mathrm{C} / \mathrm{min}$ under $100 \mathrm{ml} / \mathrm{min}$ of $\mathrm{N}_{2}$. Then a second cycle of ammonia adsorption was carried out in dry and humid conditions (c.f. Figure $\mathrm{S}_{4}$ and $\mathrm{S}_{5}$ ). Breakthrough curves for recycled compressed pellet reveal that UiO66-COOH can be regenerated at $70 \%$ and $77 \%$ in term of ammonia adsorption capacity in dry and humid conditions, respectively. Assuming that physisorption is the only adsorption mechanism, we may assume that complete generation could be obtain by increasing regeneration temperature or regeneration time at $150^{\circ} \mathrm{C}$. Finally, the robustness 
of the shaped $\mathrm{UiO}-66-\mathrm{COOH}$ has been verified. The stability upon shaking was measured by an attrition test similar to that reported by Hindocha ${ }^{12}$ and that corresponds to a downscaled device from the D4058-96 (2011) ASTM norm. After shaking the beads, the extrudates or the pellets in a cylinder for 30 minutes at $60 \mathrm{rpm}$, the weight loss due to attrition is below $2 \mathrm{wt}$.\% which is an excellent value, while for the Norit extrudates it is below $1 \mathrm{wt} . \%$.

Pellets of UiO-66-COOH were aged for 7 days at $80 \% \mathrm{RH}$ as mentioned in Hindocha et $\mathrm{al}^{12}$. Breakthrough curves of initial and aged extrudates are compared in Figure 9 and corresponding performance indicators are included in Table 1. We observe that the aged $\mathrm{UiO}-66-\mathrm{COOH}$ breaks through 8 minutes earlier with very similar uptake (34 $\mathrm{mg} / \mathrm{cm}^{3}$ compared to $33 \mathrm{mg} / \mathrm{cm}^{3}$ ). At this stage we cannot provide insights explaining the modification of the curve, which would merit a detailed study beyond the scope of this paper. Nevertheless, we want to point out that even after aging, the UiO-66-COOH pellet always outperforms the two commercial benchmark adsorbents.

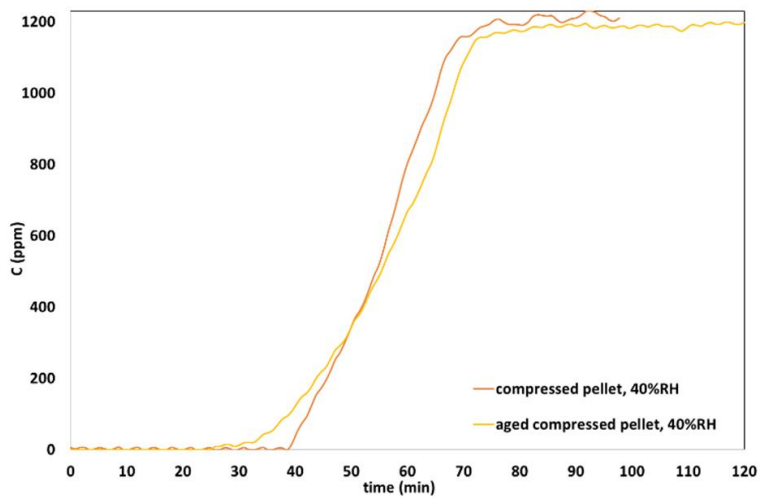

Figure 9. Comparison between ammonia breakthrough curves of fresh and aged compressed pellets of UiO66$\mathrm{COOH}$ (1200 $\mathrm{ppm} \mathrm{NH}_{3}, 40 \% \mathrm{RH}$ ).

Table 2. Ammonia adsorption capacities and breakthrough times under dry and wet conditions.

\begin{tabular}{|c|c|c|c|c|c|c|c|c|}
\hline & \multirow[t]{2}{*}{$\begin{array}{c}\text { Packed bed den- } \\
\text { sity }(425-600 \mu \mathrm{m}) \\
\left(\mathrm{g} / \mathrm{cm}^{3}\right)\end{array}$} & \multirow[t]{2}{*}{$\begin{array}{l}\text { Attrition } \\
\qquad(\%)\end{array}$} & \multicolumn{3}{|c|}{$\begin{array}{l}\text { Ammonia adsorption amount } \\
\qquad\left(\mathrm{mg} / \mathrm{cm}^{3}\right)\end{array}$} & \multicolumn{3}{|c|}{ Breakthrough time (min) } \\
\hline & & & $\mathrm{o} \% \mathrm{RH}$ & $40 \% \mathrm{RH}$ & $\begin{array}{r}600 \mathrm{ppm} \\
70 \% \mathrm{RH}\end{array}$ & $\mathrm{o} \% \mathrm{RH}$ & $40 \% \mathrm{RH}$ & $\frac{600 \mathrm{ppm}}{70 \% \mathrm{RH}}$ \\
\hline Compressed pellet & 0.6 & 1.7 & 33 & 33 & 31 & 41 & 40 & 81 \\
\hline Aged compressed pellet & 0.6 & - & & 34 & - & & 32 & - \\
\hline Beads & 0.4 & $\mathrm{o}$ & 14 & 16 & n.d. & 18 & 20 & n.d. \\
\hline $\mathrm{AC}-3 \mathrm{M}$ & 0.5 & o & 23 & 29 & 26 & 24 & 32 & 75 \\
\hline AC-Norit RZN1 & 0.7 & 0.2 & 20 & 29 & 27 & 21 & 32 & 78 \\
\hline
\end{tabular}

\section{CONCLUSION}

Metal-Organic Frameworks attract considerable interest in general and particularly for air purification. The industrialization of an adsorbent is not a straightforward task, however, because the upscaled synthesis and shaping process may alter the final performance of the original powder. Herein we have presented a high-yield synthesis of UiO66-COOH by precipitation of a non-corrosive salt. In addition, the fast reaction and the easy recovery and washing should make this process feasible at the industrial scale. The particularly elevated ammonia uptake possibly arises from a higher surface hydrophilicity resulting from a higher hydroxyl surface concentration than that found with the original synthesis in DMF.

The high grain density achieved by extrusion and compression in pellets makes $\mathrm{UiO66-COOH}$ a very efficient adsorbent for $\mathrm{NH}_{3}$ air purification that outperforms commercial benchmarks, especially in dry conditions, in which the ammonia uptake and service life of the commercial adsorbent are compromised. Mechanical stability and aging upon exposure to humidity were verified.

Full-scale testing in a separation device is beyond the scope of this paper and will be published elsewhere.

\section{ASSOCIATED CONTENT}

Supporting Information. Ammonia breakthrough curves on a mass-weighted basis and ammonia adsorption capacities, breakthrough times on a mass-weighted basis under dry and wet conditions, correlation graph between breakthrough time and uptake capacity per unit volume and TGA profile of UiO66-COOH. This material is available free of charge via the Internet at http://pubs.acs.org.

\section{AUTHOR INFORMATION}

\section{Corresponding Author}

* david.farrusseng@ircelyon.univ-lyonı.fr 
The manuscript was written through contributions of all authors. All authors have given approval to the final version of the manuscript.

\section{Funding Sources}

This work has been carried out within the ProDIA project, which has received funding from the European Union's Horizon 2020 research and innovation program under grant agreement No. 685727 .

\section{ABBREVIATIONS}

$\mathrm{C}_{\mathrm{o}} \quad$ Ammonia challenge concentration (ppm)

$\mathrm{C} \quad$ Ammonia concentration at time $(\mathrm{t})(\mathrm{ppm})$

$\mathrm{F}_{\mathrm{t}} \quad$ Total flow $(\mathrm{mL} / \mathrm{min})$

M Ammonia molar mass $(\mathrm{g} / \mathrm{mol})$

$t_{s} \quad$ time until saturation

$\mathrm{V}_{\mathrm{m}} \quad$ Molar volume $\left(\mathrm{m}^{3} / \mathrm{mol}\right)$

\section{REFERENCES}

(1) Peterson, G. W.; DeCoste, J. B.; Fatollahi-Fard, F.; Britt, D. K. Engineering UiO-66- $\mathrm{NH}_{2}$ for Toxic Gas Removal. Ind. Eng. Chem. Res. 2014, 53 (2), 701.

(2) Peterson, G. W.; Wagner, G. W.; Balboa, A.; Mahle, J.; Sewell, T.; Karwacki, C. J. Ammonia Vapor Removal by $\mathrm{Cu}_{3}$ (BTC) 2 and Its Characterization by MAS NMR. J. Phys. Chem. C 2009, 113 (31), 13906.

(3) Moghadam, P. Z.; Fairen-Jimenez, D.; Snurr, R. Efficient Identification of Hydrophobic MOFs: Application in the Capture of Toxic Industrial Chemicals. J. Mater. Chem. A 2016, 4 (2), 529.

(4) Gonçalves, M.; Sánchez-García, L.; Oliveira Jardim, E. de; Silvestre-Albero, J.; Rodríguez-Reinoso, F. Ammonia Removal Using Activated Carbons: Effect of the Surface Chemistry in Dry and Moist Conditions. Environ. Sci. Technol. 2011, 45 (24), 10605.

(5) Matthew A.Browea, Amedeo Napolitano, Jared B.De Coste, G. W. P. Filtration of Chlorine and Hydrogen Chloride Gas by Engineered UiO-66-NH2 Metal-Organic Framework. J. Hazard. Mater. 2017, 332, 162.

(6) Nijem, N.; Fürsich, K.; Bluhm, H.; Leone, S. R.; Gilles, M. K. Ammonia Adsorption and Co-Adsorption with Water in HKUST-1: Spectroscopic Evidence for Cooperative Interactions. J. Phys. Chem. C 2015, 119 (44), 24781.

(7) Jasuja, H.; Peterson, G. W.; Decoste, J. B.; Browe, M. A.; Walton, K. S. Evaluation of MOFs for Air Purification and Air Quality Control Applications: Ammonia Removal from Air. Chem. Eng. Sci. 2015, 124, 118. Kim, K. C.; Yu, D.; Snurr, R. Q. Computational Screening of Functional Groups for Ammonia Capture in Metal-Organic Frameworks. Langmuir 2013, 29 (5), 1446.

(9) Grant Glover, T.; Peterson, G. W.; Schindler, B. J.; Britt, D.; Yaghi, O. MOF-74 Building Unit Has a Direct Impact on Toxic Gas Adsorption. Chem. Eng. Sci. 2011, 66 (2), 163.

(10) Barea, E.; Montoro, C.; Navarro, J. A. R. Toxic Gas Removal-Metal-Organic Frameworks for the Capture and Degradation of Toxic Gases and Vapours. Chem. Soc. Rev. 2014, 43 (16), 5419 .

(11) DeCoste, J. B.; Peterson, G. W. Metal-Organic Frameworks for Air Purification of Toxic Chemicals. Chem. Rev. 2014, 114 (11), 5695 .

(12) Hindocha, S.; Poulston, S. Study of the Scale-Up, Formulation, Ageing and Ammonia Adsorption Capacity of MIL-10o(Fe), Cu-BTC and CPO-27(Ni) for Use in Respiratory Protection Filters. Faraday Discuss. 2017, 201 (o), 113.

(13) Joshi, J. N.; Garcia-Gutierrez, E. Y.; Moran, C. M.; Deneff, J. I.; Walton, K. S. Engineering Copper Carboxylate Functionalities on Water Stable Metal-Organic Frameworks for Enhancement of Ammonia Removal Capacities. J. Phys.
Chem. C 2017, 121 (6), 3310.

(14) Mounfield, W. P.; Taborga Claure, M.; Agrawal, P. K.; Jones, C. W.; Walton, K. S. Synergistic Effect of Mixed Oxide on the Adsorption of Ammonia with Metal-Organic Frameworks. Ind. Eng. Chem. Res. 2016, 55 (22), 6492.

(15) Gregory W. Peterson, Jared B. DeCoste, T. Grant Glover, Yougui Huang, H. J.; Walton, K. S. Effects of Pelletization Pressure on the Physical and Chemical Properties of the Metal-organic Frameworks $\mathrm{Cu}_{3}(\mathrm{BTC})_{2}$ and UiO-66. Microporous Mesoporous Mater. 2013, 179, 48.

(16) Hazardous Substance Fact Sheet for Dimethylformamide.

(17) Hurtt, M. E.; Placke, M. E.; Killinger, J. M.; Singer, A. W.; Kennedy, G. L. 13-Week Inhalation Toxicity Study of Dimethylformamide (DMF) in Cynomolgus Monkeys. Fundam. Appl. Toxicol. 1992, 18 (4), 596.

(18) Andrew R. Fox, J. M. L. Air Filter with Sorbent Particles. US Patent 9539532 B2, 2011.

(19) Beckner, M.; Dailly, A. A Pilot Study of Activated Carbon and Metal-organic Frameworks for Methane Storage. Appl. Energy 2016, 162, 506.

(20) Dhainaut, J.; Avci-Camur, C.; Troyano, J.; Legrand, A.; Canivet, J.; Imaz, I.; Maspoch, D.; Reinsch, H.; Farrusseng, D. Systematic Study of the Impact of MOF Densification into Tablets on Textural and Mechanical Properties. CrystEngComm 2017, 19 (29), 4211.

(21) DeCoste, J. B.; Peterson, G. W.; Jasuja, H.; Glover, T. G.; Huang, Y.; Walton, K. S. Stability and Degradation Mechanisms of Metal-Organic Frameworks Containing the $\mathrm{Zr6O}_{4}(\mathrm{OH})_{4}$ Secondary Building Unit. J. Mater. Chem. A 2013, 1 (18), 5642.

(22) Kandiah, M.; Nilsen, M. H.; Usseglio, S.; Jakobsen, S.; Olsbye, U.; Tilset, M.; Larabi, C.; Quadrelli, E. A.; Bonino, F.; Lillerud, K. P. Synthesis and Stability of Tagged UiO-66 Zr-MOFs. Chem. Mater. 2010, 22 (24), 6632.

(23) Wang, B.; Lv, X.-L.; Feng, D.; Xie, L.-H.; Zhang, J.; Li, M.; Xie, Y.; Li, J.-R.; Zhou, H.-C. Highly Stable Zr(IV)-Based Metal-Organic Frameworks for the Detection and Removal of Antibiotics and Organic Explosives in Water.

(24) Reinsch, H. "Green" Synthesis of Metal-Organic Frameworks. Eur. J. Inorg. Chem. 2016, 2016 (27), 4290.

(25) Gaab, M.; Trukhan, N.; Maurer, S.; Gummaraju, R.; Müller, U. The Progression of Al-Based Metal-Organic Frameworks - From Academic Research to Industrial Production and Applications. Microporous Mesoporous Mater. 2012, 157, 131.

(26) DeSantis, D.; Mason, J. A.; James, B. D.; Houchins, C.; Long, J. R.; Veenstra, M. Techno-Economic Analysis of Metal-Organic Frameworks for Hydrogen and Natural Gas Storage.

(27) Shearer, G. C.; Chavan, S.; Ethiraj, J.; Vitillo, J. G.; Svelle, S.; Olsbye, U.; Lamberti, C.; Bordiga, S.; Lillerud, K. P. Tuned to Perfection: Ironing Out the Defects in Metal-Organic Framework UiO-66. Chem. Mater. 2o14, 26 (14), 4068.

(28) Shearer, G. C.; Chavan, S.; Bordiga, S.; Svelle, S.; Olsbye, U.; Lillerud, K. P. Defect Engineering: Tuning the Porosity and Composition of the Metal-Organic Framework UiO-66 via Modulated Synthesis.

(29) Liang, W.; Coghlan, C. J.; Ragon, F.; Rubio-Martinez, M.; D’Alessandro, D. M.; Babarao, R. Defect Engineering of UiO66 for $\mathrm{CO}_{2}$ and $\mathrm{H}_{2} \mathrm{O}$ Uptake - a Combined Experimental and Simulation Study. Dalt. Trans. 2016, 45 (11), 4496.

(30) Taddei, M. When Defects Turn into Virtues: The Curious Case of Zirconium-Based Metal-Organic Frameworks. Coord. Chem. Rev. 2017, 343 (Supplement C), 1.

(31) Ghosh, P.; Colon, Y. J.; Snurr, R. Q. Water Adsorption in UiO-66: The Importance of Defects. Chem. Commun. 2014, 50 (77), 11329.

(32) Ragon, F.; Campo, B.; Yang, Q.; Martineau, C.; Wiersum, A. D.; Lago, A.; Guillerm, V.; Hemsley, C.; Eubank, J. F.; Vishnuvarthan, M.; Taulelle, F.; Horcajada, P.; Vimont, A.; Llewellyn, P.L.; Daturi, M.; Devautour-Vinot, S.; Maurin, G.; Serre, C.; Devic. T.; Clet, G. Acid-Functionalized UiO-66(Zr) 
MOFs and Their Evolution after Intra-Framework CrossLinking: Structural Features and Sorption Properties. J. Mater. Chem. A 2015, 3 (7), 3294.

(33) Lodewyckx, P. Chapter 10 Adsorption of Chemical Warfare Agents. interface Sci. Technol. 20o6, 7, 475.

(34) Khabzina, Y.; Farrusseng, D. Unravelling Ammonia Adsorption Mechanisms of Microporous Adsorbents in Humid Conditions. Microporous Mesoporous Mater. 2018, 265 (15), 143.

(35) Vandichel, M.; Hajek, J.; Vermoortele, F.; Waroquier, M.; De Vos, D. E.; Van Speybroeck, V. Active Site Engineering in UiO-66 Type Metal-Organic Frameworks by Intentional Creation of Defects: A Theoretical Rationalization. CrystEngComm 2015, 17 (2), 395.

(36) Vandichel, M.; Hajek, J.; Ghysels, A.; De Vos, A.; Waroquier, M.; Van Speybroeck, V. Water Coordination and Dehydration Processes in Defective UiO-66 Type Metal Organic Frameworks. CrystEngComm 2016, 18 (37), 7056.
(37) Valenzano, L.; Civalleri, B.; Chavan, S.; Bordiga, S.; Nilsen, M. H.; Jakobsen, S.; Lillerud, K. P.; Lamberti, C. Disclosing the Complex Structure of UiO-66 Metal Organic Framework: A Synergic Combination of Experiment and Theory. Chem. Mater. 2011, 23 (7), 1700.

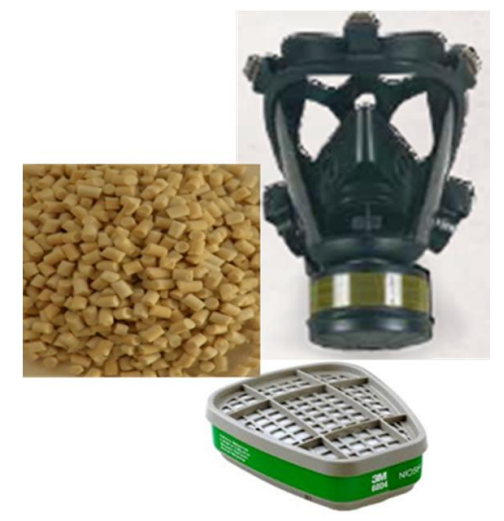

